\title{
Combined analysis of mRNA expression of ERCC1, BAG-1, BRCA1, RRM1 and TUBB3 to predict prognosis in patients with non-small cell lung cancer who received adjuvant chemotherapy
}

\author{
Xue-Feng Leng ${ }^{1 \dagger}$, Ming-Wu Chen ${ }^{1 \dagger}$, Lei Xian ${ }^{1 *}$, Lei Dai ${ }^{1}$, Guang-Yao Ma ${ }^{2}$ and Man-Hong Li ${ }^{3}$
}

\begin{abstract}
Background: The aim of this study was to investigate prognostic value of excision repair cross-complementing 1 (ERCC1), BCL2-associated athanogene (BAG-1), the breast and ovarian cancer susceptibility gene 1 (BRCA1), ribonucleotide reductase subunit M1 (RRM1) and class III $\beta$-tubulin (TUBB3) in patients with non-small cell lung cancer (NSCLC) who received platinum- based adjuvant chemotherapy.

Methods: Messenger RNA expressions of these genes were examined in 85 tumor tissues and 34 adjacent tissue samples using semi-quantitative RT-PCR. The expressions of these five genes were analyzed in relation to chemotherapy and progression-free survival (PFS) and overall survival (OS). Seventy-four patients were enrolled into chemotherapy.

Results: Patients with ERCC1 or BAG-1 negative expression had a significantly longer PFS ( $P=0.001$ and $P=0.001)$ and OS $(P=0.001$ and $P=0.001)$ than those with positive expression. Patients with negative ERCC1 and BAG-1 expression benefited more from platinum regimen $(P=0.001$ and $P=0.002)$. Patients with BRCA1 negative expression might have a longer OS $(P=0.052)$, but not PFS $(P=0.088)$ than those with BRCA1 positive expression. A significant relationship was observed between the mRNA expression of ERCC1 and BAG-1 $(P=0.042)$. In multivariate analysis, ERCC1 and BAG-1 were significantly favorable factors for PFS $(P=0.018$ and $P=0.017)$ and OS $(P=0.027$ and $P=0.022)$.
\end{abstract}

Conclusions: ERCC1 and BAG-1 are determinants of survival after surgical treatment of NSCLC, and its mRNA expression in tumor tissues could be used to predict the prognosis of NSCLC treated by platinum.

Keywords: Non-small cell lung cancer, ERCC1, BAG-1, BRCA1, RRM1, TUBB3

\section{Background}

Lung cancer is a common malignant tumor, and was the first ranked cause of cancer death in both males and females [1]. As one of the most prevalent malignant tumors in China, lung cancer has been highlighted with emphasis for cancer prevention and treatment. Recently, the combinations of cytotoxic agents (such as gemcitabine, vinorelbine, and taxane) and platinum become

\footnotetext{
*Correspondence: xianlei59@163.com

† Contributed equally

'Department of Cardiothoracic Surgery, The First Afflicted Hospital of Guangxi Medical University, 22\# Shuangyong Road, Qingxiu Region 530021 Nanning, China

Full list of author information is available at the end of the article
}

new standard for non-small-cell lung cancer (NSCLC). But the resistance to these drugs causes unsatisfactory of overall survival rate. Therefore, it is very important to understand the molecular markers of resistance to chemotherapeutic drugs.

The excision repair cross-complementing 1 (ERCC1) is a DNA damage repair gene that encodes the 5 ' endonuclease of the NER complex, and is one of the key enzymes of the nucleotide excision repair (NER) pathway which is essential for the removal of platinum-DNA adducts. Clinical studies have found that high ERCC1 expression is associated with resistance to platinum-based chemotherapy and worse prognosis in patients with advanced NSCLC 
[2]. The human BAG-1 gene is located in chromosome 9 and encodes three major BAG-1 isoforms, BAG-1S (p36), BAG-1 M (p46), and BAG-1 L (p50), which are generated via alternate translation mechanisms from the same mRNA [3]. BAG-1 is a multifunctional binding protein involved in differentiation, cell cycle, and apoptosis. BAG1 has recently been found to bind and interact with the anti-apoptotic gene Bcl-2, thereby inhibiting apoptosis [4]. Because of its affect on apoptosis, BAG-1 may play an important role in lung cancer. Further study showed that BAG-1 could be a target for lung cancer treatment of cisplatin [5]. The breast and ovarian cancer susceptibility gene1 (BRCA1) was the first breast cancer susceptibility gene identified in 1990 and was primary cloned in 1994. It has multiple roles not only in DNA damage repair but also in cell cycle regulation, transcriptional control, ubiquitination and apoptosis. In NSCLC, chemotherapeutic treatment can damage DNA through various mechanisms, the lack of functional BRCA1 can lead to increased sensitivity of the tumor cells to molecular damage, demonstrating that BRCA1 represents a predictive marker of chemotherapy response in NSCLC [6].

Ribonucleotide reductase subunit M1 (RRM1) is located on chromosome segment $11 \mathrm{p} 15.5$, it is a region with a frequent loss of heterozygosity in NSCLC. It is a component of ribonucleotide reductase, which is required for deoxynucleotide production and is also the predominant cellular determinant of the efficacy of gemcitabine, which make it to be the molecular target of gemcitabine $[7,8]$. Along with the use of antitubulin agents such as taxanes and vinorelbine, study shows there are a number of tubulin isotypes in humans, and found that class III $\beta$-tubulin (TUBB3) among them is expressed in a proportion and related to clinical outcome [9]. The expression of TUBB3 is associated with resistance of paclitaxel and docetaxel, no matter in vitro or in clinical research $[10,11]$.

Changes of gene mRNA expression during carcinogenesis may lead impact of the diagnosis, treatment, and prevention of NSCLC, it is important to understand these changes. So, in this study, we use RT-PCR to examine the expression of ERCC1, BAG-1, BRCA1, RRM1 and TUBB3 in tumor samples from patients with resected NSCLC not receiving adjuvant chemotherapy. We analyzed the relationships of these genes expression in tumors about survival time and response to chemotherapy to determine whether the expression of these molecules could be used as prognostic factors of progression-free and overall survival in this cohort of patients.

\section{Methods}

\section{Patient data}

A total of 85 patients who underwent curative surgery for NSCLC between August 2007 and April 2009 were enrolled into this study, including 85 tumor tissues and 34 adjacent tissues respectively. Among them there were 60 males and 25 females, aged 24-84 (mean 57) years. According to WHO Classification (2000), there were 25 squamous, 60 adenomatous, with 58 moderate and well differentiated (G1-G2) and 27 low differentiated (G3). Because there were only 4 cases of stage IV patients who all had surgery after single brain metastasis resected firstly, and there were no patients of stage IIIb. On account of stage IV patients were too few, so we combined 48 cases as staged I-II and 37 III-IV based on the revised AJC staging for lung cancer (1997). 28 cases had intra-thoracic lymph node metastasis (N1-N2), and 57 were negative lymph node metastasis. Additional information of surgery and chemotherapy status were all showed in (Table 1). The paracancerous tissues (defined as more than $5 \mathrm{~cm}$ away from the carcinoma tissue) taken from 34 cases were used as controls. A total of 74 Patients received at least two cycles of adjuvant chemotherapy within three months after surgery in the First Afflicted Hospital of Guangxi Medical University. 34 of 74 patients were received GP (Cisplatin $75 \mathrm{mg} / \mathrm{m}^{2}$ on day 1 , Gemcitabine $1000 \mathrm{mg} / \mathrm{m}^{2}$ on days 1,8$), 29$ of 74 patients were received NP (Cisplatin $75 \mathrm{mg} / \mathrm{m}^{2}$ on day 1 , Vinorelbine $25 \mathrm{mg} / \mathrm{m}^{2}$ on days $1+8$ ), the other 11 patients were received TP (Carboplatin AUC 6 on day 1 , Paclitaxel $175 \mathrm{mg} / \mathrm{m}^{2}$ on day 1 ), every 3 weeks. All of the tumor tissue samples were freshly frozen in liquid nitrogen immediately after surgery, and stored at $-80{ }^{\circ} \mathrm{C}$ until analysis was available. We took out the specimens from the parenchymal tissues of tumor, and we must as far as possible make the specimens keep away from the necrotic tissue. We also confirmed the HE stain results from the pathology department after surgery, which tumor sections, from the location specimens taken by us, were full of tumor cells (usually more than $60 \%-70 \%$ ). Patients who received neoadjuvant chemotherapy or neoadjuvant radiotherapy were excluded. The study protocol was approved by the Ethical Committee of the First Affiliated Hospital of Guangxi Medical University, China. All subjects signed an informed consent before entry into the study.

\section{RNA isolation and CDNA synthesis}

Fresh frozen specimens of tumor and adjacent tissues were obtained from 85 patients. Collection time from resection to freezing was required 20 minutes or less for all specimens. The fresh frozen specimens were processed for RNA isolation and reverse-transcriptase polymerase chain reaction ( $\mathrm{RT}-\mathrm{PCR}$ ) in detecting expression analysis for the ERCC1, BAG-1, BRCA1, RRM1, and TUBB3 genes. Specimens were microscopically examined to assess quality and to verify the histopathology. 
Table 1 Baseline characteristics of 85 patients with NSCLC

\begin{tabular}{|c|c|c|}
\hline Characteristics & Number & Percentage (\%) \\
\hline \multicolumn{3}{|l|}{ Gender } \\
\hline Male & 60 & 70.6 \\
\hline Female & 25 & 29.4 \\
\hline \multicolumn{3}{|l|}{ Age } \\
\hline$\leq 60$ & 53 & 62.4 \\
\hline$>60$ & 32 & 37.6 \\
\hline \multicolumn{3}{|l|}{ Nationality } \\
\hline The Han & 60 & 70.6 \\
\hline The Zhuang & 25 & 29.4 \\
\hline \multicolumn{3}{|l|}{ Histology } \\
\hline Squamous carcinoma & 25 & 29.4 \\
\hline Adenocarcinoma & 60 & 70.6 \\
\hline \multicolumn{3}{|l|}{ Differentiation } \\
\hline Well and moderate & 58 & 68.2 \\
\hline Poor & 27 & 31.8 \\
\hline \multicolumn{3}{|l|}{ Metastasis lymphatics } \\
\hline Yes & 28 & 32.9 \\
\hline No & 57 & 67.1 \\
\hline \multicolumn{3}{|l|}{ TNM stage } \\
\hline $1+\|$ & 48 & 56.5 \\
\hline$I I I+I V$ & 37 & 43.5 \\
\hline \multicolumn{3}{|l|}{ Surgery status } \\
\hline Lobectomy & 79 & 92.9 \\
\hline Pneumonectomy & 6 & 7.1 \\
\hline \multicolumn{3}{|c|}{ Chemotherapy status(74 cases) } \\
\hline GP regimens & 34 & 45.9 \\
\hline NP regimens & 29 & 39.2 \\
\hline TP regimens & 11 & 14.9 \\
\hline \multicolumn{3}{|l|}{ ECOG Performance status } \\
\hline 0 & 22 & 25.9 \\
\hline 1 & 63 & 74.1 \\
\hline
\end{tabular}

Specimens were pulverized by pulp refiner under Trizol reagent (Invitrogen). Total RNA was extracted with Trizol reagent and dissolved in DEPC water. Total RNA were reverse transcribed with RevertAid ${ }^{\mathrm{TM}}$ First Strand cDNA Synthesis Kit (Fermentas) for generation of cDNA. Gene expression for ERCC1, BAG-1, BRCA1, TUBB3, RRM1 and $\beta$-actin (internal reference gene) were performed using RT-PCR. The preliminary experiment and large sample experiment PCR were carried out as follows: an initial denaturation at $94^{\circ} \mathrm{C}$ for $3 \mathrm{~min}$ $30 \mathrm{~s}$, followed by 30 cycles of denaturation at $94^{\circ} \mathrm{C}$ for $40 \mathrm{~s}$, annealing at different temperature for different gene for $40 \mathrm{~s}$, and elongation at $72^{\circ} \mathrm{C}$ for $50 \mathrm{~s}$, then elongation $72^{\circ} \mathrm{C}$ for $7 \mathrm{~min}$ at last. The sequences of the primers used were in Table 2. All of these primers were checked and met a high specificity by BLAST function in NCBI. Confirmative PCR products through gene sequencing were used as positive controls to exclude false negative, and the no template added reaction system used as negative controls to exclude contamination of genomic DNA (Figure 1).

\section{Statistical analysis}

The data were analyzed using SPSS 17.0 software package. The correlation of gene expression with different clinical characteristics was analyzed with chi-square test or Fisher's exact test. Correlation between gene mRNA levels was evaluated by Spearman correlation coefficients. The Kaplan-Meier method and Log-rank test were used to analyze the correlation of patient survival with gene expression. Factors with significant influence on survival in univariate analysis were further analyzed by multivariate Cox regression analysis. A significance level of $P<0.05$ was used.

\section{Results}

\section{Expression of ERCC1, BAG-1, BRCA1, RRM1 and TUBB3} mRNA after surgical resection

Tumor specimens from 85 patients were available for the analysis of these genes mRNA. The specimens included 85 tumor tissues and 34 adjacent tissues. The positive rate of ERCC1 mRNA in tumor and its adjacent tissues were $58.8 \%$ and $55.9 \%$ respectively $(P=0.769)$. BAG-1 were $37.6 \%$ and $82.4 \%(P=0.000)$. BRCA1 were $16.5 \%$ and $44.1 \%(P=0.002)$. RRM1 were $30.8 \%$ and $38.2 \%(P=0.105)$. TUBB3 were $16.5 \%$ and $2.9 \%(P=$ $0.089)$. We chose some of the same samples which ERCC1 mRNA expressions were positive in order to validate the results. Expression of ERCC1 proteins was assessed by immunohistochemistry, and expression of the ERCC1 proteins was detected in the nuclei of cancer cells. All the samples selected were ERCC1 positive, including 6 squamous carcinoma and 6 adenocarcinoma (Figure 2).

\section{Correlation between ERCC1, BAG-1, BRCA1, RRM1 and TUBB3 expression and clinical features}

The expression of five genes in different clinical features were compared and summarized. It showed that the difference of these five genes were only significant between some parts of clinical features. Correlations were observed between ERCC1 expression and TNM stage $(P=0.006)$, metastasis of lymph node $(P=0.01)$, and TUBB3 expression and TNM stage $(P=0.004)$. No Correlation was observed between ERCC1, TUBB3 expression and other clinical features. Besides, No Correlation was observed between BAG-1, BRCA1, RRM1 expression and gender, age, nationality, histology, differentiation of tumor, metastasis of lymph node, TNM stage, chemotherapy status or performance status. 
Table 2 Primers for gene analysis

\begin{tabular}{|c|c|c|c|c|}
\hline Gene & Accession Number & Primer sequence $\left(5^{\prime}-3^{\prime}\right)$ & Product length & $\mathrm{Tm}$ \\
\hline \multirow[t]{2}{*}{ ERCC1 } & NM_001983.3 & Forward 5'-CCCTGGGAATTTGGCGACGTAA-3' & $273 \mathrm{bp}$ & $59^{\circ} \mathrm{C}$ \\
\hline & & Reverse 5'-CTCCAGGTACCGCCCAGCTTCC-3' & & \\
\hline \multirow[t]{2}{*}{ BAG1 } & NM_004323.5 & Forward 5'-GGCAGCAGTGAACCAGTTG-3' & $242 \mathrm{bp}$ & $54.5^{\circ} \mathrm{C}$ \\
\hline & & Reverse 5'-GCTATCTTCTCCACAGACTTCTC-3' & & \\
\hline \multirow[t]{2}{*}{ BRCA1 } & NM_007294.3 & Forward 5'-AAGGTTGTTGATGTGGAGGAG-3' & $208 \mathrm{bp}$ & $55.6^{\circ} \mathrm{C}$ \\
\hline & & Reverse 5'-CAGAGGTTGAAGATGGTATGTTG-3' & & \\
\hline \multirow[t]{2}{*}{ RRM1 } & NM_001033.3 & Forward 5'-TGGCCTTGTACCGATGCTG-3' & $161 \mathrm{bp}$ & $57.5^{\circ} \mathrm{C}$ \\
\hline & & Reverse 5'-GCTGCTCTTCCTTTCCTGTGTT-3' & & \\
\hline \multirow[t]{2}{*}{ TUBB3 } & NM_006086.3 & Forward 5'-CGGATCAGCGTCTACTAC-3' & $222 \mathrm{bp}$ & $49^{\circ} \mathrm{C}$ \\
\hline & & Reverse 5'-CACATCCAGGACCGAATC-3' & & \\
\hline \multirow[t]{2}{*}{$\beta$-actin } & NM_001101.3 & Forward 5'-CTCGCGTACTCTCTCTTTCTGG-3' & $334 \mathrm{bp}$ & $60^{\circ} \mathrm{C}$ \\
\hline & & Reverse 5'-GCTTACATGTCTCGATCCCACTTAA-3' & & \\
\hline
\end{tabular}

\section{Association between gene expression and survival after surgical resection}

The median follow-up time was 23.3 months (range 2.342.6), and the median overall survival and median PFS (progression-free survival) were 27.2 months (range 2.342.6) and 26.5 months (range 0.8-42.6), respectively. Figures 3, 4, 5 and 6 showed the Kaplan-Meier survival curves in patients positive and negative for ERCC1 and BAG-1 expression. Patients negative for ERCC1 expression had a significantly longer median progression-free (more than 42.6 vs. 15.4 months. $P=0.001$ ) and overall (more than 42.6 vs. 20.9 months. $P=0.001$ ) survival, compared with those positive for ERCC1 expression. Patients negative for BAG-1 expression had a significantly longer median progression-free survival (more than 42.6 vs. 12.9 months. $P=0.001$ ) and overall survival (more than 42.6 vs. 17.0 months. $P=0.001$ ), than those positive for BAG-1 expression. The relationships between the PFS and BRCA1, RRM1 and TUBB3 were no statistical significance $(P=0.088, P=0.116$ and $P=$ $0.271)$, and there were also the same results for OS $(P=$ $0.057, P=0.110$ and $P=0.342$ ).

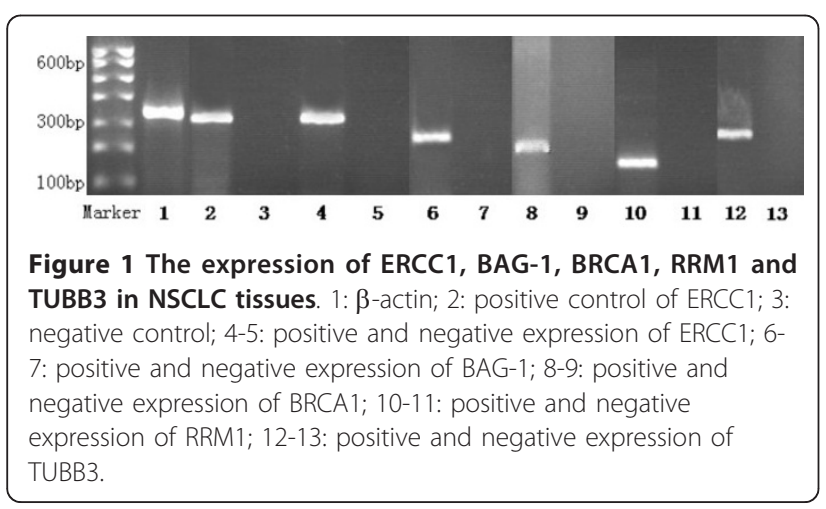

Median value of clinicopathologic factors and expression of genes of tumor samples were used as a cut-off point at univariate analysis. Univariate Cox analysis was carried out to identify the factors that were significantly associated with progression-free and overall survival (Table 3). In the univariate analysis, ERCC1 expression $(P=0.001)$, BAG-1 expression $(P=0.001)$, TNM stage $(P=0.007)$ and metastasis of lymph node $(P=0.006)$ were prognostic of progression-free survival. For overall survival, ERCC1 expression $(P=0.002)$, BAG-1 expression $(P=0.001)$, TNM stage $(P=0.008)$ and metastasis of lymph node $(P=0.007)$ were also prognostic. None of the other factors examined were statistically correlated with progression-free or overall survival for ERCC1, BAG-1 and the other three genes.

Multivariate Cox regression analysis was performed to evaluate the influence of these genes on the progression-free survival adjusting for possible confounding factors. From the results of the univariate analysis, TNM stage and metastasis of lymph node, also ERCC1 and BAG-1 were significantly correlated to the progressionfree survival (Table 4). After multivariate analysis, ERCC1 was statistically significant $(P=0.018)$ and the hazard ratio was 0.0427 (95\% CI: 0.211-0.864). BAG-1 was also statistically significant $(P=0.017)$ and the hazard ratio was 0.0474 (95\% CI: 0.257-0.874). However, the $P$-value for TNM stage $(P=0.340,95 \% \mathrm{CI}$ : 0.336 $1.457)$ and lymph node $(P=0.217,95 \% \mathrm{CI}: 0.299-1.315)$ were not statistically significant.

Multivariate Cox regression analysis was also performed for the overall survival. In addition to ERCC1, BAG-1, TNM stage and metastasis of lymph node were included in the Cox models. The other gene of TUBB3, BRCA1 and RRM1, together with the rest of patients' and clinical characteristics were not included. Negative ERCC1 and BAG-1 expression were independent and significant predictor of favorable outcome for 


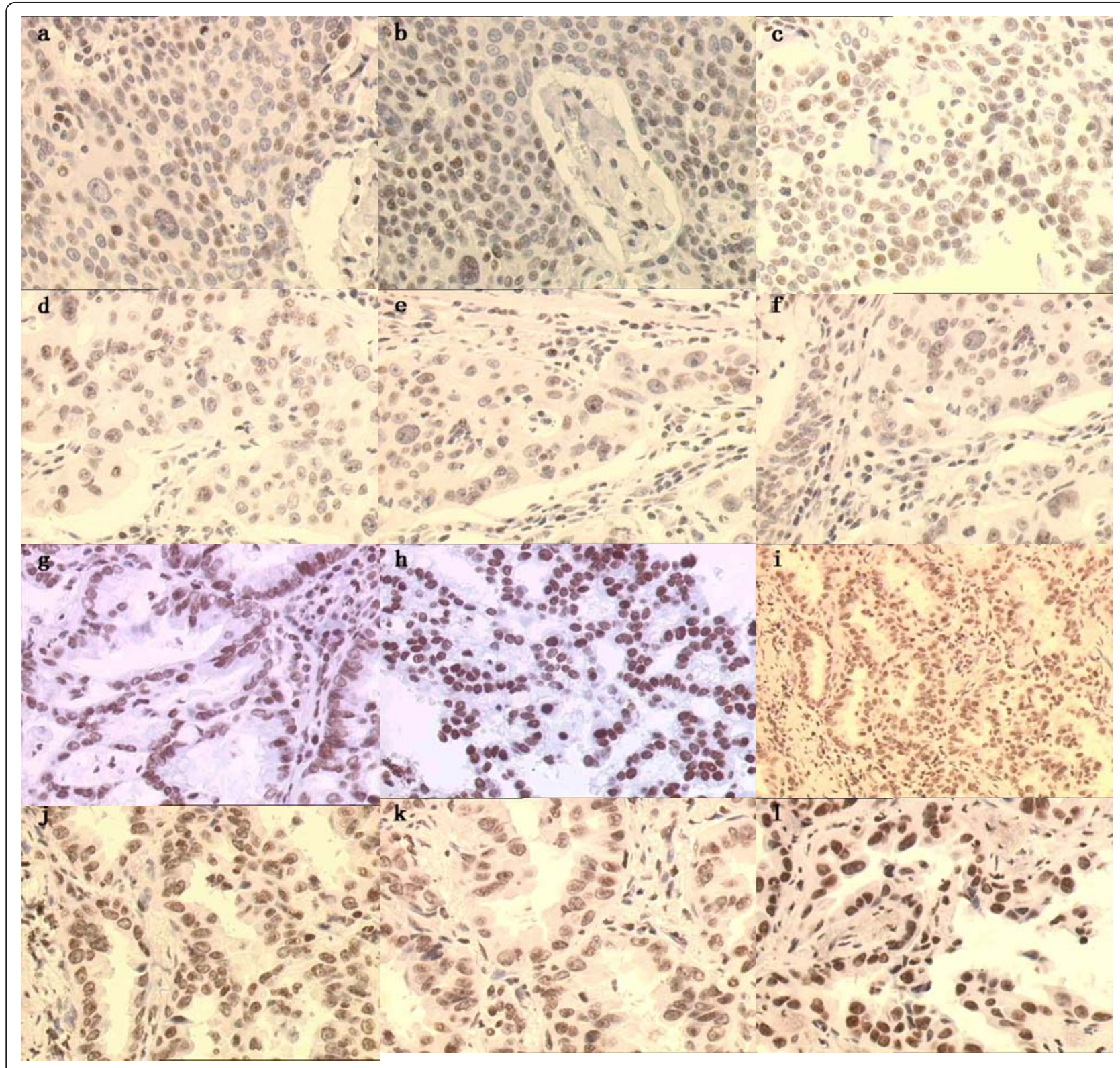

Figure 2 Immunohistochemical staining of ERCC1 proteins in NLCLC tissues. Expression of ERCC1 protein was detected in the nuclei of cancer cells. a-f: squamous carcinoma; g-l: adenocarcinoma.

overall survival $(P=0.027$ and $P=0.022)$, with a hazard ratio of ERCC1 was 0.447 (95\% CI: 0.219 $0.911)$; for BAG-1, with a hazard ratio of $0.486(95 \%$ CI: 0.262-0.901), whereas TNM stage and metastasis of lymph node had no significant association. The reason that TNM staging and lymph node were not associated with survival in the multivariate analysis might be the statistical significance of the two characteristics with survival contained in the other variables (ERCC1 and BAG-1). The other explanatory reason might be the limit of sample size.
Correlations between ERCC1, BAG-1, BRCA1, RRM1 and TUBB3 expression and the kind of adjuvant

\section{chemotherapy}

74 of 85 patients received at least two cycles of adjuvant chemotherapy, of whom 66 (89.2\%) finished at least 4 cycles. The main chemotherapy regimens included gemcitabine (GEM, 45.9\%), vinorelbine (NVB, 39.2\%) and paclitaxel (PTX, 14.9\%) combined with cisplatin (DDP)/ carboplatin (CBP).

In 74 patients treated with the regimen of cisplatin/ carboplatin, patients negative for ERCC1 expression had 


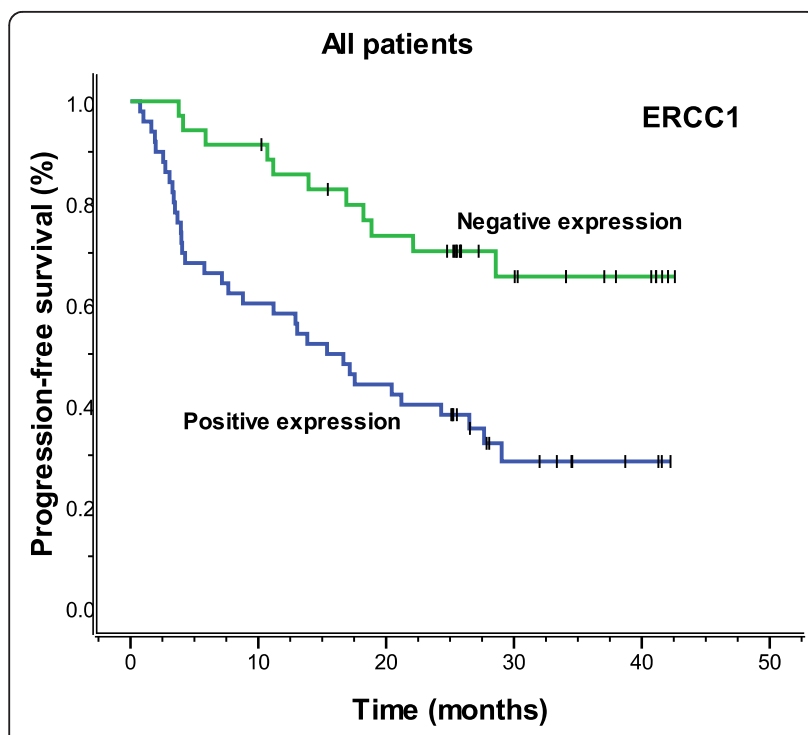

Figure 3 Progression-free survival according to ERCC1 expression (more than 42.6 vs. 15.4 months, $P=0.001$ ).

a significantly longer median progression-free (more than 42.6 months vs. 13.0 months, $P=0.001$ ) and overall (more than 42.6 months vs. 19.7 months, $P=0.001$ ) survival, compared with those positive for ERCC1 expression (Figures 7, 8). Patients negative for BAG-1 expression also had a significantly longer median progression-free survival (29.0 months vs. 11.2 months, $P=$ $0.002)$ and overall survival (32.3 months vs. 15.2 months, $P=0.002)$, than those positive for BAG-1 expression (Figures 9, 10). Whereas, there was no statistical significance in progression-free and overall survival

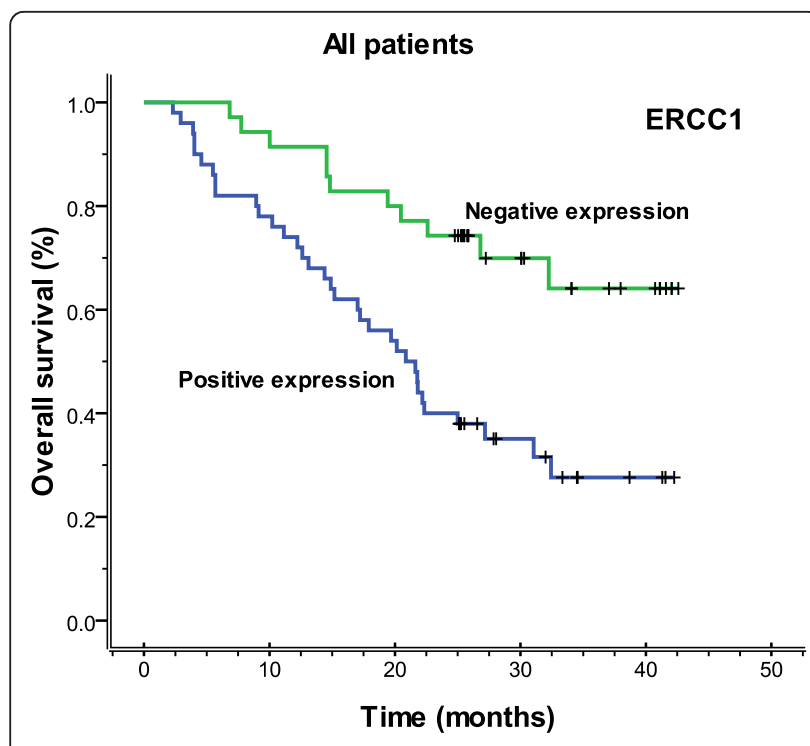

Figure 4 Overall survival according to ERCC1 expression (more than 42.6 vs. 20.9 months, $P=0.001$ )

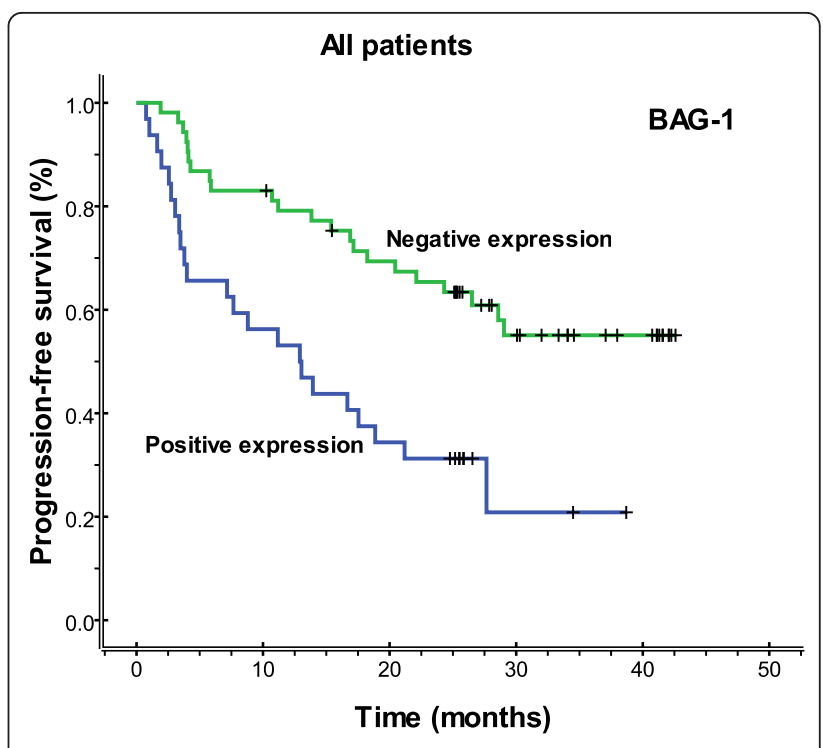

Figure 5 Progression-free survival according to BAG-1 expression (more than 42.6 vs. 12.9 months, $P=0.001$ ).

to patients with BRCA1 expression $(P=0.129$ and $P=$ 0.073 , respectively). In those treated with the regimen of gemcitabine, there was no statistical significance found in progression-free and overall survival for patients with RRM1 expression $(P=0.310$ and $P=0.299$, respectively). In the anti-tubulin regimen group of vinorelbine or paclitaxel, no statistical significance was found in progression-free and overall survival between the negative and positive expression of TUBB3 $(P=0.745$ and $P$ $=0.742$, respectively); in the same measure, no statistical significance was found in progression-free and overall

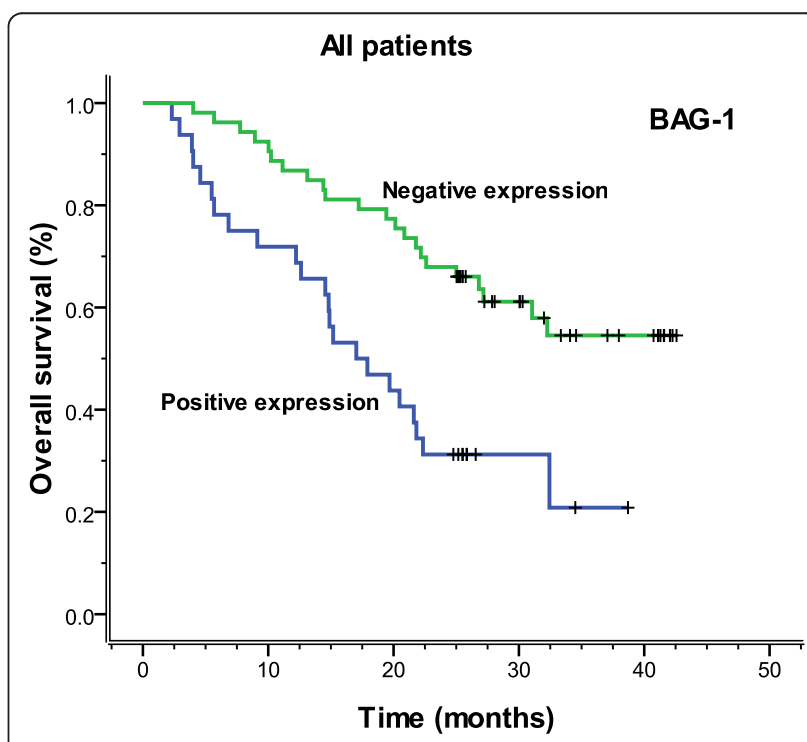

Figure 6 Overall survival according to BAG-1 expression (more than 42.6 vs. 17.0 months, $P=0.001$ ) 
Table 3 Univariate analysis of Clinicopathological features, tumor markers, and patient survival

\begin{tabular}{ccccc}
\hline Variable & PFS HR (95\% Cl) & $P$ value & OS HR (95\% Cl) & $P$ value \\
\hline Gender (Male vs. Female) & $1.370(0.744-2.524)$ & 0.313 & $1.341(0.713-2.421)$ & 0.381 \\
\hline Age $(\leq 60$ vs. $\mathbf{6 0})$ & $1.433(0.789-2.604)$ & 0.237 & $1.450(0.798-2.635)$ & 0.223 \\
\hline Nationality (The Han vs. The Zhuang) & $0.929(0.480-1.800)$ & 0.827 & $0.964(0.497-1.867)$ & 0.912 \\
\hline Histology (Squamous carcinoma vs. Adenocarcinoma) & $0.541(0.267-1.095)$ & 0.088 & $0.559(0.276-1.133)$ & 0.106 \\
\hline Differentiation (Well and moderate vs. Poor) & $0.992(0.528-1.866)$ & 0.980 & $0.953(0.506-1.795)$ & 0.881 \\
\hline Metastasis lymphatics (Yes vs. No) & $0.429(0.236-0.780)$ & $0.006^{* *}$ & $0.435(0.238-0.793)$ & $0.007^{* *}$ \\
\hline TNM stage (I+II vs. III+IV) & $2.267(1.257-4.090)$ & $0.007^{* *}$ & $2.217(1.227-4.003)$ & $0.008^{* *}$ \\
\hline ERCC1 (positive vs. negative) & $0.326(0.165-0.645)$ & $0.001^{* *}$ & $0.333(0.169-0.660)$ & $0.002^{* *}$ \\
\hline BAG-1 (positive vs. negative) & $0.367(0.202-0.665)$ & $0.001^{* *}$ & $0.363(0.200-0.658)$ & $0.001^{* *}$ \\
\hline BRCA1 (positive vs. negative) & $0.546(0.270-1.105)$ & 0.093 & $0.505(0.250-1.021)$ & 0.057 \\
\hline RRM1 (positive vs. negative) & $0.539(0.314-1.143)$ & 0.120 & $0.590(0.309-1.126)$ & 0.110 \\
\hline TUBB3 (positive vs. negative) & $0.665(0.319-1.383)$ & 0.275 & $0.701(0.338-1.458)$ & 0.342 \\
\hline
\end{tabular}

** represent $P<0.01$

survival between the negative and positive expression of BRCA1 ( $P=0.612$ and $P=0.389$, respectively).

\section{Correlation of ERCC1 and BAG-1 expression}

There were 25 cases that expressed both ERCC1 and BAG-1 and 27 cases that expressed neither. As shown in Table 5, the correlation was found between ERCC1 and BAG-1 gene expression $(P=0.042, \mathrm{r}=0.247)$. All 52 patients of both positive and negative expression were received adjuvant chemotherapy. For both negative mRNA expression had a significantly longer median progression-free (more than 42.6 months vs. 8.8 months, $P=0.000$ ) and overall (more than 42.6 months vs. 17.0 months, $P=0.000$ ) survival, compared with those positive for both ERCC1 and BAG-1 expression (Figures 11, 12).

\section{Discussion}

Along with the development of theory and practice in treatment of chemotherapy with resected NSCLC, we have already known the combination of two cytotoxic drugs, like a platinum and a non-platinum agent, is the standard first-line treatment of NSCLC patients [12]. However, because of the high rate of toxicity observed and associated with drug resistance, treatment response rate and median overall survival are not satisfactory. This appears to be gene of chemoresistance, which plays an important role in the after surgery treatment. So, some markers detection is a key for chemotherapy in NSCLC patients.

Platinum drugs mainly exert their cytotoxicity by forming bulky intra-strand platinum-DNA adducts and inter-strand cross-link of the two DNA strands. Removal of these adducts from genomic DNA and repair of interstrand cross-links in DNA and recombination processes are mediated by components of different DNA repair pathways. ERCC1 is a key factor involved in nuclear excision repair (NER) for platinum induced adducts [13]. There is observation of platinum resistance in lung cancer A549 cells lines with high expression of ERCC1 [14], and increased clinical evidence that overexpression of ERCC1 in NSCLC inhibits platinum efficacy. In addition to ERCC1 negative tumors appear to benefit from cisplatin based chemotherapy, it also gains benefit from overall survival as a prognostic factor $[2,15,16]$. As a predictive factor, a phase III trial in NSCLC showed better PFS and OS in the low genotypic than in the high genotypic group, and the patients in the low genotypic group also had a trend toward a lower risk of progression than those in the control arm [17]. Although it had been identified that ERCC1 positive could be associated with resistance to platinum based chemotherapy, however, some studies reported that ERCC1 expression had correlation with improved prognosis $[18,19]$. This discrepancy may be due to differences of experimental processing, regional disparity or technical issues. In our

Table 4 Multivariate analysis of Clinicopathological features, tumor markers, and patient survival

\begin{tabular}{lllll}
\hline Variable & PFS HR $(\mathbf{9 5} \% \mathrm{Cl})$ & $\boldsymbol{P}$ value & OS HR (95\% CI) & $P$ value \\
\hline ERCC1 (positive vs. negative) & $0.427(0.211-0.864)$ & $0.018^{*}$ & $0.447(0.219-0.911)$ & $0.027^{*}$ \\
BAG-1 (positive vs. negative) & $0.474(0.257-0.874)$ & $0.017^{*}$ & $0.486(0.262-0.901)$ & $0.022^{*}$ \\
Metastasis lymphatics (Yes vs. No) & $0.627(0.299-1.315)$ & 0.217 & $0.654(0.352-1.370)$ & 0.260 \\
TNM stage (I + II vs. III + IV) & $0.699(0.336-1.457)$ & 0.340 & $1.442(0.691-2.984)$ & 0.324 \\
\hline
\end{tabular}

* represent $P<0.05$ 


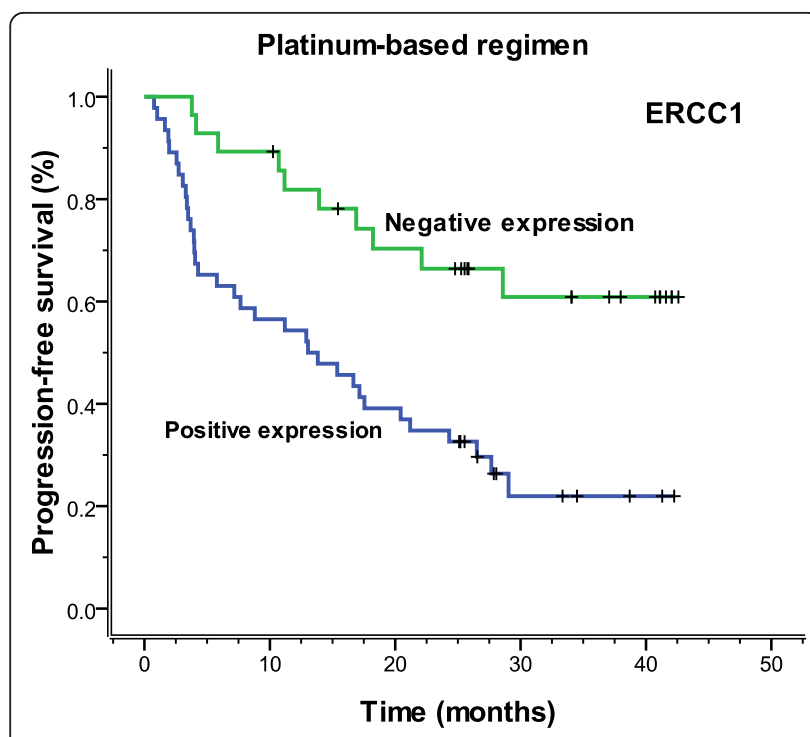

Figure 7 Progression-free survival according to ERCC1 expression which was based on platinum chemotherapy (more than 42.6 vs. 13.0 months, $P=0.001$ )

study, expression of ERCC1 in stage III + IV was higher than stage I + II $(P=0.006)$. This was also happened in lymph node metastasis compared to no metastasis $(P=$ 0.01), which like Ota et al. reported [20]. The available data indicate ERCC1 positive patients might present a poor prognosis, and ERCC1 expression might appear to be an advanced stage event.

The BAG-1, as an anti-apoptotic function, exhibits positive expression in many malignant tumors. It binds to the cytosolic domain of the growth factor receptors

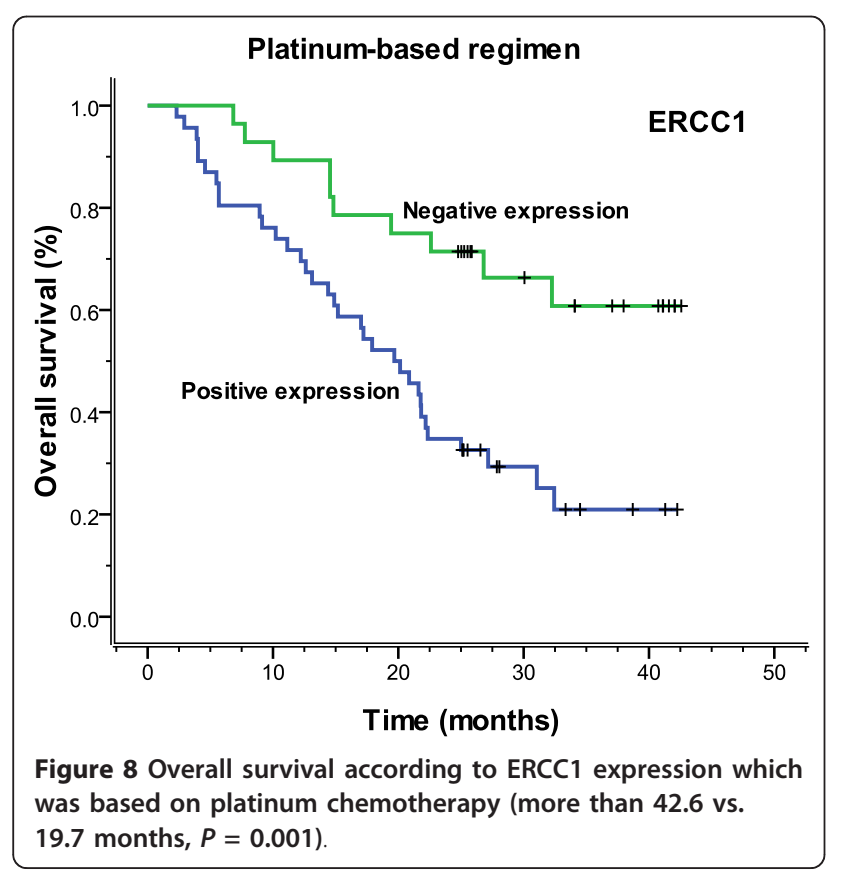

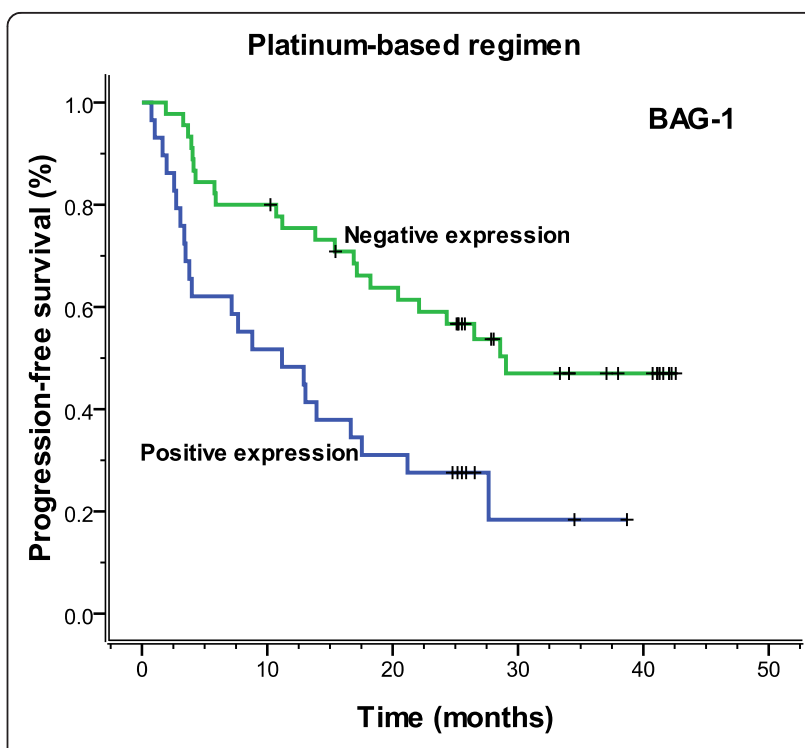

Figure 9 Progression-free survival according to BAG-1 expression which was based on platinum chemotherapy $(29.0$ vs. 11.2 months, $P=0.002$ ).

on the cell surface, enhancing the protection from cell death triggered by these receptors. However, it binds to Bcl-2 and heat shock protein (HSP) and modulates their function in the cytosol, and it binds to nuclear hormone receptors for inhibiting hormone-induced apoptosis in the nucleus [21]. Further exploration shows overexpression of BAG-1 suppresses activation of caspases and apoptosis induced by chemotherapeutic agents [22]. As expected, experiment performed in lung cancer cells

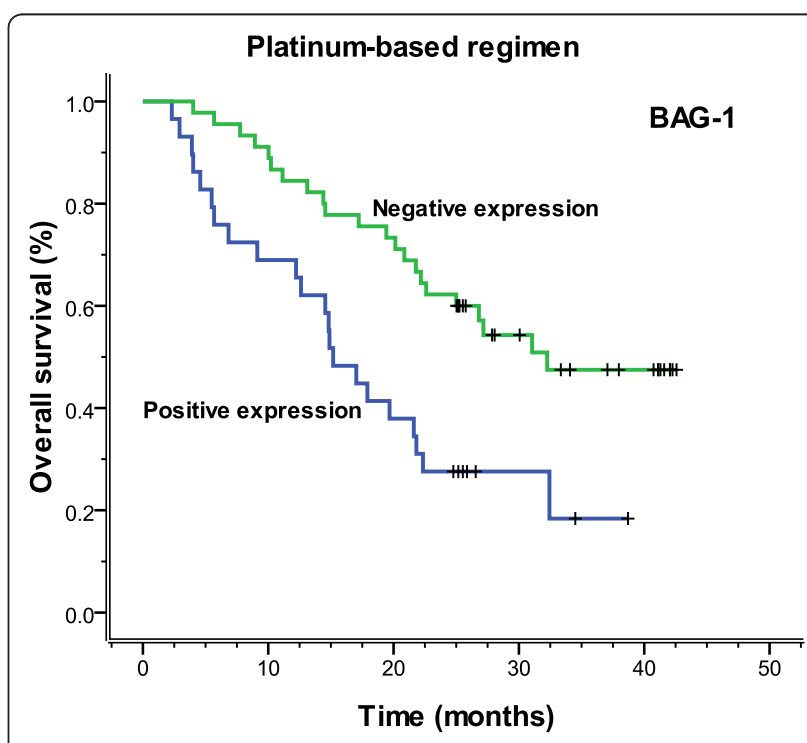

Figure 10 Overall survival according to BAG-1 expression which was based on platinum chemotherapy (32.3 vs. 15.2 months, $P=0.002$ ). 
Table 5 Correlation between expression of ERCC1 and BAG-1

\begin{tabular}{llll}
\hline Gene & \multicolumn{3}{l}{ ERCC1 } \\
\hline & + & - \\
\hline & + & 25 & 8 \\
\hline BAG-1 & & & \\
\hline & - & 25 & 27 \\
\hline
\end{tabular}

indicates silencing of BAG-1 gene can sensitize lung cancer cells to cisplatin-induced apoptosis [5]. In this study, the positive BAG-1 expression correlated significantly with progression-free and overall survival in patients treated by platinum. As we described, current research has proven expression of BAG-1 indicates poor prognosis [23]. Whereas, Rorke et al. [24] reported high expression of BAG-1 may correlate to better prognosis in NSCLC. The difference between findings may be due to different choices of treatment and different components of data.

BRCA1 is implicated in NER, which was discussed in the part of ERCC1, it also associates with double-strand break repair and mismatch repair, indicating its crucial role in DNA repair [25]. It has been indicated that BRCA1 presents different sensitivity to different chemotherapy agent in vitro study. The negative expression of BRCA1 results in high sensitivity to cisplatin, whereas its positive expression increases sensitivity to antimicrotubule agents [26]. In clinical research, it was found that patients whose tumors had BRCA1 expression would have significantly poorer survival and should be

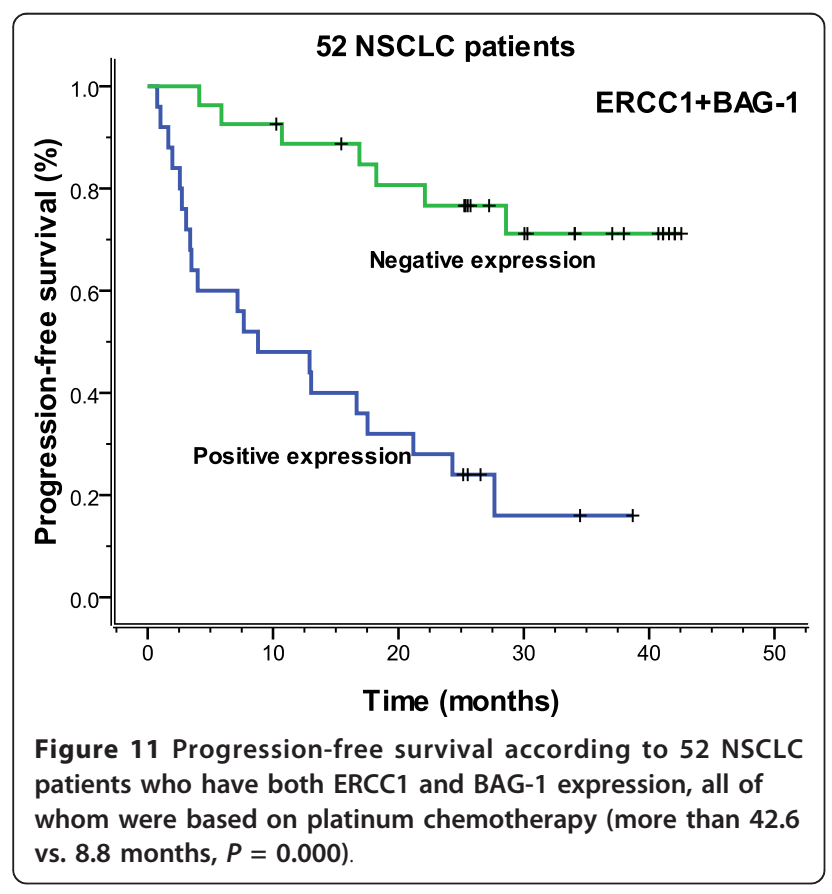

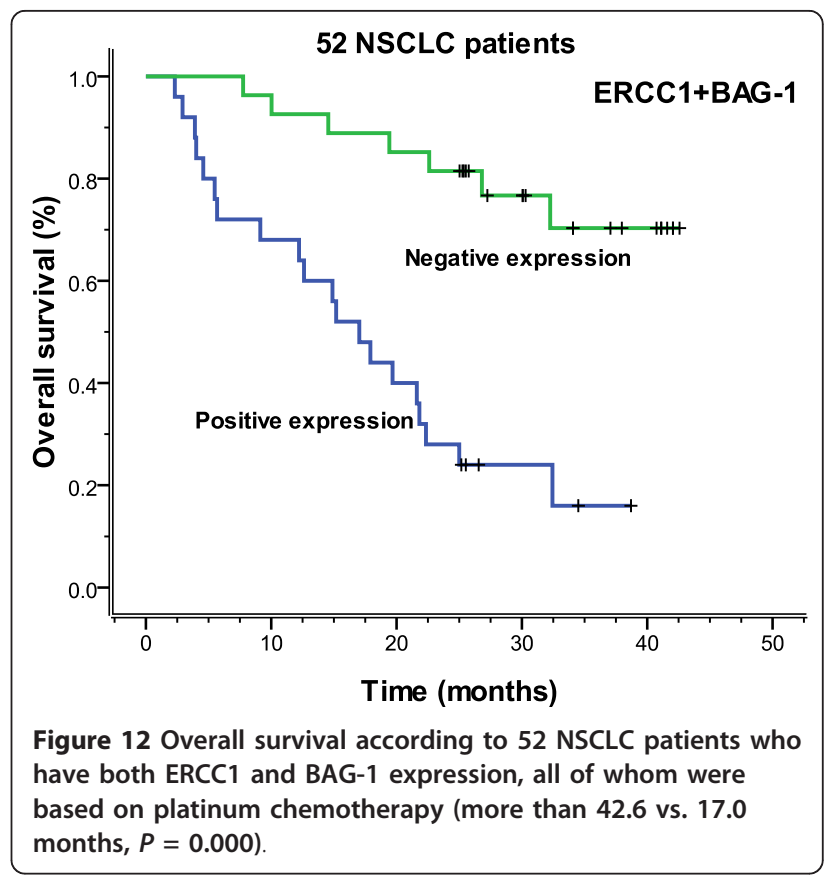

candidates for adjuvant chemotherapy [27]. Median survival was 11 months for 38 patients with low BRCA1, treated with cisplatin plus gemcitabine; 9 months for 40 patients with intermediate BRCA1, treated with cisplatin plus docetaxel; and 11 months for 33 patients with high BRCA1, treated with docetaxel alone. Two-year survival was $41.2 \%, 15.6 \%$ and $0 \%$, respectively, which had manifested the potential predictive role of BRCA1 in a recent non-randomized phase II clinical trial [28]. Our findings indicate that BRCA1 expression might correlate with OS and platinum treatment based OS, however, there was no statistical significance $(P=0.052$ vs. $P=0.073)$. Nevertheless, the results tend to migrate to statistical significant directions accompanied extension of followup time and expansion of sample size.

In addition, as the gene sensitive to cisplatin or other DNA damaging agents, expression of ERCC1 is closely related to BRCA1, no matter in breast cancer or in NSCLC $[29,30]$. But there is not much more studies indicate correlations between BAG-1. Our findings demonstrate a strong correlation between ERCC1 and BAG-1. Therefore, it is plausible that patients with the expression of ERCC1 and BAG-1 present a poor prognosis and the lack of its expression would receive more benefit from non platinum based chemotherapy.

As one of the targets of gemcitabine, RRM1 also have roles in DNA repair systems like ERCC1 and BRCA1. It encodes the regulatory subunit of ribonucleotide reduction of ribonucleoside diphosphates to the corresponding deoxyribonucleotides [31]. In earlier study, it suggested continuous exposure of lung cancer cell lines to increasing 
amounts of gemcitabine resulted in increased expression of RRM1 [32]. In addition, another research showed reduced RRM1 expression increased sensitivity to gemcitabine in lung cancer cell lines, and found RRM1 expression in tumor is a major predictor of disease response to gemcitabine chemotherapy during a prospective phaseII clinical trial with NSCLC [8]. TUBB3 is investigated and recognized as a role in resistance to antitubulin agents. The report shows TUBB3 is expressed in high levels in lung cancer cell lines, and by using RNAi technology, it was found that TUBB3 mediates sensitivity to paclitaxel in NSCLC cells, and high levels of TUBB3 expression are associated with paclitaxel and docetaxel resistance in vitro $[11,33,34]$. Our result showed that TUBB3 was more frequently observed in stage I + II than in stage III + IV patients $(P=0.004)$. But Recent data suggested expression of TUBB3 was related to advanced stage NSCLC [35]. In this study, no correlation of chemotherapy between RRM1 and TUBB3, or the survival of the patients was found. It might be caused by the limitation of different cycles of adjuvant chemotherapy taken by patients and other interferences like number of samples and only one clinical center involved in our study.

\section{Conclusions}

In summary, to better overcome the problems related to drug resistance and to improve the clinical outcome of advanced NSCLC patients, relationship between drug resistance caused by gene expression and prognosis of patients received adjuvant chemotherapy must be investigated. Our findings indicate ERCC1 and BAG-1 are prognostic factors for progression-free and overall survival, and may be predictive biomarkers for platinum based chemotherapy in NSCLC patients. Accompanied by enlargement of sample size, BRCA1 might also be an indicator the above-mentioned. Although the approach of RT-PCR has a better feasibility and repeatability, and we have quality control of the laboratory. It remain has many factors influence the experimentation to cause the false positive results. Moreover, 85 patients were certainly few and follow-up time was short to be able to conclude firmly on any of the findings in our study, particularly using multivariate analysis. However, because of patients with negative expression of these genes indeed receive more benefit from platinum based chemotherapy in our study, the combined detection of the mRNA expression of these genes might better individualize the efficacy of chemotherapy and improve survival in this common and vital cancer.

\section{Funding}

This research was supported by Guangxi Scientific research and technology development projects (Grant No. 10124001A-44)

\section{Acknowledgements}

This research was supported by Guangxi Scientific research and technology development projects (Grant No. 10124001A-44). Thanks for data sorting and processing by Guang-Yao Ma and Man-Hong Li.

\section{Author details}

${ }^{1}$ Department of Cardiothoracic Surgery, The First Afflicted Hospital of Guangxi Medical University, 22\# Shuangyong Road, Qingxiu Region 530021 Nanning, China. ${ }^{2}$ Department of Cardiothoracic Surgery, The First Afflicted Hospital of Luohe Medical college, 462000 Luohe, China. ${ }^{3}$ Department of Cardiothoracic Surgery, Central Hospital of Loudi, 417000 Loudi, China.

\section{Authors' contributions}

XFL: RT-PCR operations, statistical analysis, collection of patients' information, manuscript drafting. MWC: Research planning, statistical analysis, manuscript drafting. LX: Research planning, surgery and maintenance of patients'

database. LD: RT-PCR operations. GYM: RT-PCR operations, data sorting and processing. MHL: Patients' data sorting and processing. All authors read and approved the final manuscript.

\section{Competing interests}

The authors declare that they have no competing interests.

Received: 17 January 2012 Accepted: 23 March 2012

Published: 23 March 2012

\section{References}

1. Chen W, Zhang S, Zou X: Evaluation on the incidence, mortality and tendency of lung cancer in China. Thoracic Cancer 2010, 1:35-40.

2. Olaussen KA, Dunant A, Fouret P, Brambilla E, Andre F, Haddad V, Taranchon E, Filipits M, Pirker R, Popper HH, et al: DNA repair by ERCC1 in non-small-cell lung cancer and cisplatin-based adjuvant chemotherapy. N Engl J Med 2006, 355:983-991.

3. Takayama S, Sato T, Krajewski S, Kochel K, Irie S, Milian JA, Reed JC: Cloning and functional analysis of BAG-1: A novel Bcl-2-binding protein with anti-cell death activity. Cell 1995, 80:279-284.

4. Krajewska M, Turner BC, Shabaik A, Krajewski S, Reed JC: Expression of BAG-1 protein correlates with aggressive behavior of prostate cancers. Prostate 2006, 66:801-810.

5. Liu H, Liang Y, Li Y, Wang J, Wu H, Wang Y, Tang SC, Chen J, Zhou Q: Gene silencing of BAG-1 modulates apoptotic genes and sensitizes lung cancer cell lines to cisplatin-induced apoptosis. Cancer Biol Ther 2010, 9:832-840.

6. Kennedy RD, Quinn JE, Johnston PG, Harkin DP: BRCA1: mechanisms of inactivation and implications for management of patients. Lancet 2002, 360:1007-1014.

7. Bepler G, Gautam A, Mclntyre LM, Beck AF, Chervinsky DS, Kim YC, Pitterle DM, Hyland A: Prognostic significance of molecular genetic aberrations on chromosome segment 11 p15.5 in non-small-cell lung cancer. J Clin Oncol 2002, 20:1353-1360.

8. Bepler G, Kusmartseva I, Sharma S, Gautam A, Cantor A, Sharma A, Simon G: RRM1 modulated in vitro and in vivo efficacy of gemcitabine and platinum in non-small-cell lung cancer. J Clin Oncol 2006, 24:4731-4737.

9. Dumontet C, Isaac S, Souquet PJ, Bejui-Thivolet F, Pacheco Y, Peloux N, Frankfurter A, Luduena R, Perol M: Expression of class III beta tubulin in non-small cell lung cancer is correlated with resistance to taxane chemotherapy. Bull Cancer 2005, 92:E25-E30.

10. Azuma K, Sasada T, Kawahara A, Takamori S, Hattori S, Ikeda J, Itoh K, Yamada A, Kage M, Kuwano M, Aizawa H: Expression of ERCC1 and class III [beta]-tubulin in non-small cell lung cancer patients treated with carboplatin and paclitaxel. Lung Cancer 2009, 64:326-333.

11. Burkhart CA, Kavallaris M, Band Horwitz S: The role of beta-tubulin isotypes in resistance to antimitotic drugs. Biochim Biophys Acta 2001, 1471:01-09.

12. Crino L, Weder W, van Meerbeeck J, Felip E: Early stage and locally advanced (non-metastatic) non-small-cell lung cancer: ESMO Clinical Practice Guidelines for diagnosis, treatment and follow-up. Ann Oncol 2010, 21(Suppl 5):v103-v115.

13. Gossage L, Madhusudan S: Current status of excision repair cross complementing-group 1 (ERCC1) in cancer. Cancer Treat Rev 2007, 33:565-577. 
14. Li J-J, Ding Y, Li D-D, Peng R-Q, Feng G-K, Zeng Y-X, Zhu X-F, Zhang X-S: The overexpression of ERCC-1 is involved in the resistance of lung cancer cells to cetuximab combined with DDP. Cancer Biol Ther 2009, 8:1914-1921.

15. Li J, Li ZN, Yu LC, Bao QL, Wu JR, Shi SB, Li XQ: Association of expression of MRP1, BCRP, LRP and ERCC1 with outcome of patients with locally advanced non-small cell lung cancer who received neoadjuvant chemotherapy. Lung Cancer 2010, 69:116-122.

16. Wang X, Zhao J, Yang L, Mao L, An T, Bai H, Wang S, Liu X, Feng G, Wang J: Positive expression of ERCC1 predicts a poorer platinum-based treatment outcome in Chinese patients with advanced non-small-cell lung cancer. Medical Oncology 2010, 27:484-490.

17. Cobo M, Isla D, Massuti B, Montes A, Sanchez JM, Provencio M, Vinolas N, Paz-Ares L, Lopez-Vivanco G, Munoz MA, et al: Customizing cisplatin based on quantitative excision repair cross-complementing 1 mRNA expression: a phase III trial in non-small-cell lung cancer. J Clin Oncol 2007, 25:2747-2754.

18. Zheng Z, Chen T, Li X, Haura E, Sharma A, Bepler G: DNA synthesis and repair genes RRM1 and ERCC1 in lung cancer. N Engl J Med 2007, 356:800-808.

19. Lee KH, Min HS, Han SW, Oh DY, Lee SH, Kim DW, Im SA, Chung DH, Kim YT, Kim TY, et al: ERCC1 expression by immunohistochemistry and EGFR mutations in resected non-small cell lung cancer. Lung Cancer 2008, 60:401-407.

20. Ota S, Ishii G, Goto K, Kubota K, Kim YH, Kojika M, Murata Y, Yamazaki M, Nishiwaki Y, Eguchi K, Ochiai A: Immunohistochemical expression of BCRP and ERCC1 in biopsy specimen predicts survival in advanced non-smallcell lung cancer treated with cisplatin-based chemotherapy. Lung Cancer 2009, 64:98-104.

21. Cutress Rl, Townsend PA, Brimmell M, Bateman AC, Hague A, Packham G: BAG-1 expression and function in human cancer. Br J Cancer 2002, 87:834-839.

22. Takayama S, Reed JC: Molecular chaperone targeting and regulation by BAG family proteins. Nat Cell Biol 2001, 3:E237-E241.

23. Liu H, Bai Y, Liu B, Wang Z, Wang M, Zhou Q, Chen J: The expression of BAG-1 and its clinical significance in human lung cancer. Zhongguo Fei $\mathrm{Ai}$ Za Zhi 2008, 11:489-494.

24. Rorke S, Murphy S, Khalifa M, Chernenko G, Tang SC: Prognostic significance of BAG-1 expression in nonsmall cell lung cancer. Int 」 Cancer 2001, 95:317-322.

25. Taron M, Rosell R, Felip E, Mendez P, Souglakos J, Ronco MS, Queralt C, Majo J, Sanchez JM, Sanchez JJ, Maestre J: BRCA1 mRNA expression levels as an indicator of chemoresistance in lung cancer. Hum Mol Genet 2004, 13:2443-2449.

26. Quinn JE, James CR, Stewart GE, Mulligan JM, White P, Chang GKF, Mullan PB, Johnston PG, Wilson RH, Harkin DP: BRCA1 mRNA Expression Levels Predict for Overall Survival in Ovarian Cancer after Chemotherapy. Clin Cancer Res 2007, 13:7413-7420.

27. Bartolucci R, Wei J, Sanchez JJ, Perez-Roca L, Chaib I, Puma F, Farabi R, Mendez P, Roila F, Okamoto T, et al: XPG mRNA expression levels modulate prognosis in resected non-small-cell lung cancer in conjunction with BRCA1 and ERCC1 expression. Clin Lung Cancer 2009, 10:47-52.

28. Rosell R, Perez-Roca L, Sanchez JJ, Cobo M, Moran T, Chaib I, Provencio M, Domine M, Sala MA, Jimenez U, et al: Customized treatment in non-smallcell lung cancer based on EGFR mutations and BRCA1 mRNA expression. PLoS One 2009, 4:e5133.

29. Kim D, Jung W, Koo JS: The expression of ERCC1, RRM1, and BRCA1 in breast cancer according to the immunohistochemical phenotypes. $J$ Korean Med Sci 2011, 26:352-359.

30. Su C, Zhou S, Zhang L, Ren S, XU J, Zhang J, Lv M, Zhou C: ERCC1, RRM1 and BRCA1 mRNA expression levels and clinical outcome of advanced non-small cell lung cancer. Med Oncol 2010, 28:1411-1417.

31. Pitterle DM, Kim YC, Jolicoeur EM, Cao Y, O'Briant KC, Bepler G: Lung cancer and the human gene for ribonucleotide reductase subunit M1 (RRM1). Mamm Genome 1999, 10:916-922

32. Davidson JD, Ma L, Flagella M, Geeganage S, Gelbert LM, Slapak CA: An Increase in the Expression of Ribonucleotide Reductase Large Subunit Is Associated with Gemcitabine Resistance in Non-Small Cell Lung Cancer Cell Lines. Cancer Res 2004, 64:3761-3766.
33. Liu B, Staren ED, Iwamura T, Appert HE, Howard JM: Mechanisms of taxotere-related drug resistance in pancreatic carcinoma. J Surg Res 2001, 99:179-186.

34. Gan PP, Pasquier E, Kavallaris M: Class III beta-tubulin mediates sensitivity to chemotherapeutic drugs in non small cell lung cancer. Cancer Res 2007, 67:9356-9363.

35. Koh Y, Jang B, Han SW, Kim TM, Oh DY, Lee SH, Kang CH, Kim DW, Im SA Chung DH, et al: Expression of class III beta-tubulin correlates with unfavorable survival outcome in patients with resected non-small cell lung cancer. J Thorac Oncol 2010, 5:320-325.

doi:10.1186/1756-9966-31-25

Cite this article as: Leng et al.: Combined analysis of mRNA expression of ERCC1, BAG-1, BRCA1, RRM1 and TUBB3 to predict prognosis in patients with non-small cell lung cancer who received adjuvant chemotherapy. Journal of Experimental \& Clinical Cancer Research 2012 $31: 25$

\section{Submit your next manuscript to BioMed Central and take full advantage of:}

- Convenient online submission

- Thorough peer review

- No space constraints or color figure charges

- Immediate publication on acceptance

- Inclusion in PubMed, CAS, Scopus and Google Scholar

- Research which is freely available for redistribution 